\title{
Patient considerations in early management of Parkinson's disease: focus on extended-release pramipexole
}

This article was published in the following Dove Press journal:

Patient Preference and Adherence

13 January 2012

Number of times this article has been viewed

\author{
Fatai Kunle Salawu \\ Division of Neurology, Department \\ of Medicine, Federal Medical Centre \\ Yola, Adamawa State, Nigeria
}

\begin{abstract}
This article reviews the role of an extended-release formulation of pramipexole in the treatment of Parkinson's disease at an early stage. Pramipexole is a nonergot $D_{2} / D_{3}$ synthetic aminobenzothiazole derivative that is effective as monotherapy in early disease and as an adjunct to levodopa in patients with motor fluctuations. Although levodopa is the current "gold standard" for treatment of Parkinson's disease, its effectiveness fades rapidly and its use results in serious motor fluctuations (on-off, wearing-off, freezing, involuntary movements) for most patients with the disease. Pramipexole has selective actions at dopamine receptors belonging to the $\mathrm{D}_{2}$ subfamily, where it possesses full activity similar to dopamine itself. Its preferential affinity for the $\mathrm{D}_{3}$ receptor subtype could contribute to its efficacy in the treatment of both the motor and psychiatric symptoms of Parkinson's disease. The best approach to medical management of early Parkinson's disease remains controversial. While enormous progress has been made in the treatment of the disease, challenges still remain. A variety of treatment-related and patientrelated factors must be taken into account when making these decisions. The current approach to treatment of early Parkinson's disease depends in part on individual patient factors, including age, severity and nature of symptoms and their impact, presence of cognitive dysfunction, possible underlying behavioral factors predisposing to impulse control disorders, and other comorbidities. Today, the once-daily extended-release formulation of pramipexole offers the advantages of easy continuous delivery of drug and convenience to patients, particularly early in the disease when monotherapy is the rule. Thus, a new "levodopa-sparing" paradigm for treating Parkinson's disease may now be possible, whereby patients are initially treated with pramipexole and levodopa is added only as necessary.

Keywords: Parkinson's disease, treatment, pramipexole, dopamine agonist, motor complications, continuous dopaminergic stimulation
\end{abstract}

\section{Introduction}

Parkinson's disease, named for James Parkinson who wrote a monograph entitled "An essay on the shaking palsy" in $1817,{ }^{1}$ is a progressively disabling neurodegenerative condition that causes dopamine deficiency in the nigrostriatal system and is treated most commonly by dopamine replacement with the precursor levodopa, but agonists at dopamine receptor sites are used as initial therapy in the early stages of the disease. ${ }^{2}$ Pathologically, there is a loss of neurons within the substantia nigra pars compacta and other subcortical nuclei, associated with widespread Lewy bodies, ${ }^{3}$ which are abnormal aggregates of proteins that develop inside neurons. Parkinson's disease manifests clinically after loss of approximately $50 \%$ of dopaminergic neurons. ${ }^{4}$
Correspondence: Fatai K Salawu of Medicine, Federal Medical Centre Yola 64000I, Adamawa State, Nigeria Tel +23408036154516

Email dr_abdulsalawu@yahoo.com 
Parkinson's disease is the second most common neurodegenerative disorder, affecting $1.4 \%$ of the population over the age of 55 years. ${ }^{5}$ An estimated 5 million people throughout the world have Parkinson's disease, with one million individuals each in the US and in Europe having the disorder. With the aging of the population and the substantial increase in the number of at-risk individuals older than 60 years, it is anticipated that the prevalence of Parkinson's disease will increase dramatically in the coming decades. ${ }^{6}$ Interestingly, a large prospective study found that incidence rates rise steeply through to age 89 years; then lifetime risk plateaus after age 90 years. $^{7}$ The incidence of Parkinson's disease has been reported to be higher in men than in women, but only among patients older than 60 years. ${ }^{8}$ Several studies suggest a higher incidence of Parkinson's disease in whites than in African-Americans or Latin Americans. This may be due to true biological differences in the risk of Parkinson's disease or to underdiagnosis because of barriers to health care, such as education or cultural beliefs about health and aging. ${ }^{9}$

Many of the motor manifestations of the disease can be attributed to the disappearance of dopamine-producing neurons in the substantia nigra pars compacta and the consequent severe depletion of dopamine in the striatum into which the nigral nerve terminals project. The degree of degeneration of these dopaminergic terminals correlates best with the bradykinesia aspect of Parkinson's disease, which is an essential diagnostic criterion for the disease, rather than tremor or rigidity. ${ }^{10}$ The cardinal clinical manifestations of Parkinson's disease are tremor, rigidity, bradykinesia, and gait dysfunction (postural instability). Usually there is asymmetry, with one side being affected first and remaining worse throughout the disease. It is now appreciated that Parkinson's disease is also associated with many nonmotor features, including autonomic dysfunction, pain and sensory disturbances, mood disorders, sleep impairment, and dementia. Nonmotor symptoms may present before motor symptoms are manifest. ${ }^{11}$

Parkinson's disease is characterized pathologically by degeneration of dopaminergic neurons in the substantia nigra pars compacta coupled with intracytoplasmic proteinaceous inclusions known as Lewy bodies. Parkinson's disease is also associated with extensive nondopaminergic pathology, which involves cholinergic neurons of the nucleus basalis of Meynert, norepinephrine neurons of the locus coeruleus, serotonin neurons in the midline raphe, as well as neurons in the cerebral cortex, brainstem, spinal cord, and peripheral autonomic nervous system. ${ }^{12}$ Indeed, studies suggest that nondopaminergic pathology, particularly in the dorsal motor nucleus and olfactory regions, precedes the onset of dopaminergic pathology in the substantia nigra. ${ }^{13}$

Effective treatment of the motor symptoms of Parkinson's disease involves compensating the striatum and output nuclei of the basal ganglia for loss of degenerating nigrostriatal dopaminergic input. There is now accumulating evidence that the combination of progressive pathology in Parkinson's disease, changes in drug pharmacodynamics, and the pulsatile manner in which short-acting dopaminergic agents stimulate striatal dopamine receptors are key contributing factors in priming of the basal ganglia for induction of motor complications. ${ }^{14}$

Logically, once the diagnosis of Parkinson's disease is made, treatment should be started immediately with an effective neuroprotective agent. However, to date, no treatment has been proven to slow progression of Parkinson's disease, although this is an area of ongoing research. ${ }^{15}$ The 20 th century witnessed unheralded advancements in medical and surgical management for Parkinson's disease, the foremost of which was the discovery that the dopamine precursor, levodopa, substantially improves motor symptoms. ${ }^{16}$ A majority of patients experience motor fluctuations, dyskinesia, or other complications after 5 years of treatment and the frequency increases as the disease duration is prolonged. Off periods of wearing-off and on-off and severe dyskinesia markedly interfere with daily activities and compromise the quality of life of patients with Parkinson's disease. Much research into developing additional symptomatic medications has been focused on avoiding these complications. ${ }^{17}$ Neurologists have several choices of drugs that have been shown to be effective for the treatment of the symptoms of Parkinson's disease. ${ }^{17}$ Dopamine agonists are being used increasingly as first-line treatment for the disease, but there remains uncertainty about their clinical and cost-effectiveness relative to levodopa. ${ }^{17}$ Long-acting dopamine agonists provide more physiological dopaminergic stimulation. The recommendation supported by evidence from randomized controlled trials is to start treatment with a dopamine agonist and add levodopa when it becomes necessary. ${ }^{18-20}$ In this review, the benefits of using dopamine agonists in the management of early Parkinson's disease would be discussed, along with recent evidence of the convenience of once-daily use of an extended-release formulation of pramipexole.

\section{Dopamine agonists}

The use of oral dopamine agonists for the treatment of Parkinson's disease dates back to the 1970s when bromocriptine was first introduced. ${ }^{17}$ The symptomatic efficacy of dopamine agonists to treat Parkinson's disease is 
firmly established, and several studies have also shown that early use of these drugs as initial monotherapy is associated with a reduced long-term incidence of motor complications (ie, motor fluctuations and dyskinesia) compared with levodopa. ${ }^{19,21-24}$ Although this evidence has led to dopamine agonists being classified as first-line options for initial monotherapy in early Parkinson's disease in many national and international guidelines, ${ }^{25,26}$ there have also been concerns about the safety profile of these drugs in the long term. These concerns relate to the risk of developing daytime somnolence, hallucinations, peripheral edema, hypersexuality, impulse control disorders, and heart valve fibrosis. ${ }^{17}$ In the past decade, nonergot dopamine agonists have largely supplanted the ergot agonists as the dopamine agonists of choice for the treatment of Parkinson's disease. Pramipexole and ropinirole are the two most widely used drugs. Ropinirole has been approved for the treatment of early Parkinson's disease in a transdermal (patch) delivery formulation, but had been voluntarily withdrawn from the market in the US because of a tendency for the drug to crystallize in the patch. ${ }^{27}$ Although the use of dopamine agonists to improve motor symptoms remains the basis of treatment, ${ }^{28}$ the design of pharmacotherapy is evolving toward more continuous drug delivery to provide more continuous stimulation of striatal dopamine receptors ${ }^{29}$ and more convenience for patients.

\section{Pramipexole}

The dopamine agonist pramipexole ${ }^{30}\left(\right.$ Sifrol $^{\circledR}$, Mirapex $^{\circledR}$, Mirapexin $^{\circledR}$, and Pexola ${ }^{\circledR}$; Boehringer Ingelheim $\mathrm{GmbH}$, Ingelheim, Germany) is a nonergot D2/D3 synthetic aminobenzothiazole derivative that is effective as monotherapy in early Parkinson's disease and as an adjunct to levodopa in patients with motor fluctuations and advanced idiopathic Parkinson's disease. ${ }^{31-33}$ An extended-release formulation (Sifrol Retard ER ${ }^{\circledR}$, Mirapex ER ${ }^{\circledR}$, Mirapexin ER ${ }^{\circledR}$, and Pexola $\mathrm{ER}^{\circledR}$; Boehringer Ingelheim $\mathrm{GmbH}$ ) that could be taken once daily might provide an effective and simple alternative treatment. Once-daily therapies have been shown to promote better adherence (compliance), ${ }^{34-36}$ which in Parkinson's disease might lead to off-time ${ }^{37}$ and theoretically a reduced risk for motor complications. ${ }^{38}$ Initial monotherapy with pramipexole is among the first-line treatment approaches to early Parkinson's disease recommended in major international guidelines as a means to delay the occurrence of motor complications induced by levodopa. ${ }^{25,39}$ Pramipexole is also efficacious and safe as adjunctive therapy to reduce motor response oscillations in levodopa-treated patients with Parkinson's disease. ${ }^{39-42}$ However, recent studies have clearly established that once-daily drugs are associated with the highest value for total or daily drug adherence and, in particular, timing adherence. ${ }^{36}$ The currently available immediate-release formulation of pramipexole is taken three times daily. Dosing frequency has been identified as a major factor for suboptimal drug adherence in Parkinson's disease. ${ }^{43}$ A once-daily extended-release formulation of pramipexole and three times daily pramipexole immediate-release have similar exposure over 24 hours, and might therefore offer benefits in terms of convenience, compliance, and mode of dopamine delivery. ${ }^{43}$ The new extended-release formulation of pramipexole which has been launched in Europe and the US improves ease of use and compliance and provides a more continuous therapeutic effect over 24 hours. ${ }^{44}$ The extended-release formulation is associated with fewer fluctuations in plasma pramipexole concentrations over this period. The United States Food and Drug Administration (FDA) has approved pramipexole dihydrochloride extended-release tablets for the signs and symptoms of early idiopathic Parkinson's disease. ${ }^{44}$ Pramipexole extended-release for early Parkinson's disease is a positive development in the treatment of this disease. This new once-daily treatment has a more convenient dosing schedule, offering greater flexibility as someone with early Parkinson's disease plans his or her day. Extended-release pramipexole dihydrochloride tablets for oral administration are available in strengths of $0.375,0.75,1.5,3$, and $4.5 \mathrm{mg} .{ }^{31}$ In general, patients tend to prefer once-daily dosing to a more frequent regimen because of convenience. Before initiating any treatment, the benefit-risk ratio to the individual patient must be considered. For pramipexole to be used in the treatment of Parkinson's disease, it is necessary to take into account the available evidence regarding its symptomatic efficacy, effect on delaying long-term levodopa-related motor complications, beneficial effect on nonmotor symptoms such as depression, and its safety and tolerability profile. Findings from clinical studies show that pramipexole extended-release is superior to placebo and has benefits comparable with the currently available pramipexole immediate-release in early Parkinson's disease. Pramipexole extended-release improved the symptoms of Parkinson's disease in three well designed trials in adults with early or advanced disease, as measured by changes from baseline in the sum of the Unified Parkinson's Disease Rating Scale parts II and II subtotal scores. In one of the studies, in early Parkinson's disease, the feasibility of an overnight switch from pramipexole immediate-release to the once-daily extended-release formulation was studied. ${ }^{45}$ In a 9-week study, the majority of patients with early Parkinson's disease who were receiving stable pramipexole immediate-release 
treatment were successfully switched to pramipexole extendedrelease. Both formulations were safe and well tolerated, with the rate of adverse events being generally similar to that with pramipexole immediate-release. In patients with early Parkinson's disease, several prospective, double-blind, controlled trials have shown initiation of therapy with a longacting dopamine agonist to be associated with a lower risk of motor complications compared with initiation on levodopa. ${ }^{46,47}$ Once the decision is made that dopaminergic therapy should be initiated (for whatever reason), several factors impact on the choice of treatment, particularly whether to use levodopa or a dopamine agonist. The long-standing belief that levodopa has potential neurotoxic effects, primarily through its ability to enhance oxidative stress on remaining dopaminergic neurons has been largely abandoned. ${ }^{48}$ Thus, the advantage of the "levodopa-sparing" effects of dopamine agonists in reducing oxidative stress has little current support. The strongest justification for initiation of treatment with a dopamine agonist is the repeated demonstration that this treatment approach is associated with a significant reduction in the risk of developing motor complications, particularly dyskinesias, compared with levodopa. ${ }^{19,20,22,23}$ Dopamine agonists have been regularly shown to provide less improvement on rating scale evaluations than levodopa, although it has been argued that the differences demonstrated in the early treatment trials were not clinically meaningful. ${ }^{19,49}$ The cognitive state of the patient and their financial resources should be taken into account when deciding on initial therapy for Parkinson's disease.

Young-onset Parkinson's disease (YOPD) is arbitrarily defined as symptom onset between the ages of 21 and 39 years inclusive. However, different studies have used an upper age cut-off of anywhere from 40 to 50 years. Juvenile-onset Parkinson's disease is defined as Parkinson's disease onset before the age of 21 years. ${ }^{50}$ YOPD is uncommon, but in Japan the prevalence is higher. Diagnostic considerations in YOPD include Wilson's disease, toxins, genetic Parkinson's disease, and other neurodegenerative disorders. YOPD patients differ from the typical onset Parkinson's disease patients, with dystonia being more common. In addition, they have a long course of disease and are more prone to levodopa-induced dyskinesia. Some studies have shown that up to $95 \%$ of patients develop dyskinesia after 5 years of levodopa therapy. ${ }^{22}$ Therefore, YOPD patients are good candidates for therapies other than levodopa. These include anticholinergics, amantadine, monoamine oxidase B inhibitors, and dopamine agonists. The widely practiced initiation of dopaminergic treatment with dopamine agonists to delay dyskinesias is still probably justified in young-onset patients who develop dyskinesias almost universally within the early treatment years. ${ }^{50}$ YOPD patients are frequently good candidates for surgical treatment of Parkinson's disease. Currently, deep brain stimulation of the subthalamic nucleus is offered to this group of patients with remarkable success as far as motor symptoms are concerned. It is essential to listen to the experiences of patients.

An interesting study compared quality of life between a group of patients who started with dopaminergic drugs versus a group left untreated for 18 months after diagnosis. The quality of life was higher in the group treated early. ${ }^{51}$ When considering the issue of when to start symptomatic treatment, both patients and clinicians should be guided primarily by the current functional disabilities experienced by the patients during their everyday activities (eg, employment, hobbies, and self-care). The optimal time frame for onset of therapy has not been clearly defined. Once parkinsonian signs start to have an impact on the patient's life, initiation of treatment is recommended. For each patient, the choice between the numerous effective drugs available is based on a subtle combination of subjective and objective factors. ${ }^{27}$ These factors include considerations related to the drug (eg, efficacy for symptomatic control of parkinsonism/ prevention of motor complications, safety, practicality, costs), to the patient (eg, symptoms, age, needs, expectations, experience, comorbidity, socioeconomic level), and to his/her environment (including drug availability according to national markets in the European Union, and variability in economic and health insurance systems). However, based on the available level of evidence alone, two main issues are usually considered when initiating a symptomatic therapy for early Parkinson's disease, ie, symptomatic control of parkinsonism and prevention of motor complications.

\section{Conclusion}

Many physicians routinely use dopamine agonists in early Parkinson's disease because they provide symptomatic benefits with a low risk of motor complications. It is important to recognize that the treatment of Parkinson's disease is highly individual and that the physician must use his or her best judgment and consider the wishes of the patient in making therapeutic decisions. Pramipexole is generally well tolerated and efficacious for treating motor symptoms in both early and advanced Parkinson's disease. Its efficacy and tolerability are similar in African-Americans, Asians, Caucasians, and Hispanics. ${ }^{52}$ As initial treatment, pramipexole may delay the onset of dyskinesias by delaying the start 
of levodopa therapy. It appears to have beneficial effects on nonmotor symptoms, such as depression, and it may improve treatment-resistant tremor, anhedonia, and weight loss. ${ }^{52}$,Pramipexole seems to have neuroprotective effects in vitro and in animal models, but these findings have not been replicated in humans. Compared with levodopa, pramipexole therapy is associated with a higher risk for developing hallucinations, somnolence (and indirectly, attacks of sudden onset of sleep), impulse control disturbances, and peripheral edema, but not cardiac valvular disease. The risk for adverse events increases with patient age, pramipexole dose, severity of Parkinson's disease, concomitant combination therapy, and comorbidity, especially cardiovascular. Continued pharmacovigilance in respect to adverse events, especially increased somnolence, cardiac valvulopathy, and psychiatric effects is necessary. Although pramipexole therapy is more costly than levodopa, the cost-effectiveness increases over time due to a higher gain in quality of life. More research is needed regarding the neuroprotective potential of pramipexole and its impact on cognition, apathy, fatigue, quality of life, and treatment costs in Parkinson's disease. Pramipexole seems especially well suited for younger patients with Parkinson's disease ( $<65$ years), without cognitive disturbances, with low comorbidity, at high risk for developing dyskinesias, and with particular features of Parkinson's disease shown to be responsive to pramipexole. Pramipexole new extended-release offers an important opportunity to simplify drug regimens for patients with Parkinson's disease while maintaining symptom control. Finally, it should be reiterated that pramipexole and other drugs that are used to alleviate symptoms in early Parkinson's disease are unlikely to modify disease progression, and future therapies must combine symptomatic and disease-modifying agents.

\section{Disclosure}

The author reports no conflicts of interest in this work.

\section{References}

1. Parkinson J. An essay on the shaking palsy. London, UK: Whittingham and Rowland, for Sherwood, Neely and Jones; 1817.

2. Olanow CW, Koller WC. An algorithm (decision tree) for the management of Parkinson's disease: treatment guidelines. Neurology. 1998;50(Suppl 3):S1-S57.

3. Gibbs WR, Lees AJ. The significance of the Lewy body in the diagnosis of idiopathic Parkinson's disease. Neuropathol Appl Neurobiol. 1989; $15: 27-44$

4. Jellinger K. Overview of morphological changes in Parkinson's disease. Adv Neurol. 1987;45:1-18.

5. de Rijk MC, Breteler MM, Graveland GA, et al. Prevalence of Parkinson's disease in the elderly: the Rotterdam Study. Neurology. 1995;45:2143-2146.
6. Lilienfeld DE, Perl DP. Projected neurodegenerative disorder mortality in the United States, 1990-2040. Neuroepidemiology. 1993;12:219-228.

7. Driver JA, Logroscino G, Gaziano JM, Kurth T. Incidence and remaining lifetime risk of Parkinson disease in advanced age. Neurology. 2009;72:432-443.

8. Taylor KS, Cook JA, Counsel CE. Heterogeneity in male to female risk for Parkinson's disease. J Neurol Neurosurg Psychiatry. 2007; 78:905-906.

9. Dahodwala N, Siderowf A, Xie M, et al. Racial differences in the diagnosis of Parkinson's disease. Mov Disord. 2009;24:1200-1205.

10. Shinotoh H, Uchida $Y$, Ito $H$, et al. Relationship between striatal [123] beta-CIT binding and four major clinical signs in Parkinson's disease. Ann Nucl Med. 2000;14:199-203.

11. Chaudhuri KR, Healy DG, Schapira AH. National Institute for Clinical Excellence. Non-motor symptoms of Parkinson' disease: diagnosis and management. Lancet Neurol. 2006;5:235-245.

12. Forno LS. Neuropathology of Parkinson's disease. J Neuropathol Exp Neurol. 1996;55:259-272.

13. Braak H, Del Tredici K, Rub U, et al. Staging of brain pathology related to sporadic Parkinson's disease. Neurobiol Aging. 2003;24:197-211.

14. Stocchi F. Continuous dopaminergic stimulation and novel formulation of dopamine agonists. J Neurol. 2011;258:S316-S322.

15. Lang AE. When and how should treatment be started in Parkinson disease? Neurology. 2009;72:S39-S43.

16. Cotzias GC, Papavasiliou PS, Gellene R. Experimental treatment of Parkinsonism with L-dopa. Neurology. 1968;18:276-277.

17. Antonini A, Tolosa E, Mizuno Y, Yamamoto M, Poewe WH. A reassessment of risks and benefits of dopamine agonists in Parkinson's disease. Lancet Neurol. 2009;8:929-937.

18. Guttman M, Stewart D, Hussey D, et al. Pramipexole vs L-dopa as initial treatment for Parkinson's disease: a 4-year randomized controlled trial. Arch Neurol. 2004;61:1044-1053.

19. Rascol O, Brooks DJ, Korczyn AD, De Deyn PP, Clarke CE, Lange AE. A five-year study of the incidence of dyskinesia in patients with early Parkinson's disease who were treated with ropinirole or L-dopa. N Engl J Med. 2000;342:1484-1491.

20. Rinne UK, Bracco F, Chouza C, et al. Early treatment of Parkinson's disease with carbegoline delays the onset of motor-complications. Results of a double-blind L-dopa controlled trial. Drugs. 1998;55(Suppl 1): 23-30.

21. Parkinson Study Group. Pramepexole vs levodopa as initial treatment for Parkinson disease: a randomized control trial. JAMA. 2000; 284:1931-1938.

22. Holloway RG, Shoulson I, Fahn S, et al. Pramipexole vs levodopa as initial treatment for Parkinson's disease: a 4-year randomized controlled trial. Arch Neurol. 2004;61:1044-1053.

23. Oertel WH, Wolters E, Sampaio C, et al. Pergolide versus levodopa monotherapy in early Parkinson's disease patients: The PELMOPET study. Mov Disord. 2005;21:343-353.

24. Bracco F, Battaglia A, Chouza C, et al. The long-acting dopamine receptor agonist carbegoline in early Parkinson's disease: final results of a 5-year, double-blind levodopa-controlled study. CNS Drugs. 2004;18:733-746.

25. Horstink M, Tolosa E, Bonuccelli U, et al. Review of the therapeutic management of Parkinson's disease. Report of a joint task force of the European Federation of Neurological Societies and the Movement Disorder Society-European Section. Part 1: early (uncomplicated) Parkinson's disease. Eur J Neurol. 2006;13:1170-1185.

26. Miyasaki JM, Martin W, Suchowersky O, Weiner WJ, Lang AE. Practice parameter initiation of treatment for Parkinson's disease: an evidence-based review. Report of the Quality Standards Subcommittee of the American Academy of Neurology. Neurology. 2002;58: $11-17$.

27. Olanow CW, Stern MB, Sethi K. The scientific and clinical basis for the treatment of Parkinson disease (2009). Neurology. 2009;72(21 Suppl 4): S1-S136. 
28. Olanow CW, Watts RL, Koller WC. An algorithm (decision tree) for the management of Parkinson's disease: Treatment guidelines. Neurology. 2001;56(Suppl 5):S1-S88.

29. Olanow CW, Obeso JA, Stocchi F. Continuous dopamine-receptor treatment of Parkinson's disease: Scientific rationale and clinical implications. Lancet Neurol. 2006;5:677-687.

30. Piercey MF. Pharmacology of pramipexole, a dopamine D3-preferring agonist useful in treating Parkinson's disease. Clin Neuropharmacol. 1998;21:141-151.

31. Jenner P, Konen-Bergmann M, Schepers C, Haertter S. Pharmacokinetics of a once-daily extended-release formulation of pramipexole in healthy male volunteers: three studies. Clin Ther. 2009;31:2698-2711.

32. Lieberman A, Ranhosky A, Korts D. Clinical evaluation of pramipexole in advanced Parkinson's disease: results of a double-blind, placebocontrolled, parallel-group study. Neurology. 1997;49:162-168.

33. Moller JC, Oertel WH, Koster J, Pezzoli G, Provinciali L. Longterm efficacy and safety of pramipexole in advanced Parkinson's disease: results from a European multicentre trial. Mov Disord. 2005; 20:602-610.

34. Leopold NA, Polansky M, Hurka MR. Drug adherence in Parkinson's disease. Mov Disord. 2004;19:513-517.

35. Grosset KA, Bone I, Grosset DG. Suboptimal medication adherence in Parkinson's disease. Mov Disord. 2005;20:1502-1507.

36. Grosset D, Antonini A, Canesi M, et al. Adherence to antiparkinson medication in a multicentre European study. Mov Disord. 2009; 24:826-832.

37. Pahwa R, Stacy MA, Factor SA, et al. Ropinirole 24-hour prolonged release: randomized, controlled study in advanced Parkinson disease. Neurology. 2007;68:1108-1115.

38. Olanow W, Schapiro AH, Rascol O. Continuous dopamine-receptor stimulation in early Parkinson's disease. Trends Neurosci. 2000; Suppl 23:S117-S126.

39. National Institute for Health and Clinical Excellence. Parkinson's disease: diagnosis and management in primary and secondary care. Available at: guidance.nice.org.uk/CG35. Accessed September 22, 2011.

40. Pahwa R, Factor SA, Lyons KE, et al. Practice parameter: treatment of Parkinson disease with motor fluctuations and dyskinesia (an evidencebased review): report of the Quality Standards Subcommittee of the American Academy of Neurology. Neurology. 2006;66:983-995.
41. Horstink M, Tolosa E, Bonuccelli U, et al. Review of the therapeutic management of Parkinson's disease: report of a joint task force of the European Federation of Neurological Societies (EFNS) and the Movement Disorder Society-European Section (MDS): part II: late (complicated) Parkinson's disease. Eur J Neurol. 2006;13:1186-1202.

42. Goetz CG, Poewe W, Rascol O, Sampaio C. Evidence-based medical review update: pharmacological and surgical treatments of Parkinson's disease: 2001 to 2004. Mov Disord. 2005;20:523-539.

43. Poewe W, Rascol O, Barone P, et al. Extended-release pramipexole in early Parkinson disease: A 33-week randomized controlled trial. Neurology. 2011;77:759-766.

44. Antonini A, Barone P, Ceravolo R, Fabbrini G, Tinazzi M, Abbruzzese G. Role of pramipexole in the management of Parkinson's disease. CNS Drugs. 2010;24:829-941.

45. Rascol O, Barone P, Hauser RA, et al; Pramipexole Switch Study Group. Efficacy, safety and tolerability of overnight switching from immediateto once daily extended-release pramipexole in early Parkinson's disease. Mov Disord. 2010;25:2326-2332.

46. Whone AL, Watts RL, Stoessl AJ, et al. Slower progression of Parkinson's disease with ropinirole versus levodopa: the REAL-PET study. Ann Neurol. 2002;54:93-101.

47. Parkinson Study Group. Dopamine transporter brain imaging to assess the effects of pramipexole vs levodopa on PD progression. JAMA 2002;287:1653-1661.

48. Ahlskog JE. Beating a dead horse - dopamine and Parkinson disease. Neurology. 2007;69:1701-1711.

49. Holloway R, Shoulson I, Kieburtz K, et al. Pramipexole vs levodopa as initial treatment for Parkinson's disease - a randomized controlled trial. JAMA. 2000;60:1931-1938.

50. Quinn N, Critchley P, Marsden CD. Young onset Parkinson's disease. Mov Disord. 1987;2:36-91.

51. Grosset D, Taurah L, Burn DJ, et al. A multicentre longitudinal observational study of changes in self-reported health status in people with Parkinson's disease left untreated at diagnosis. J Neurol Neurosurg Psychiatry. 2007;78:2007-2009.

52. Constantinesen R. Update on the use of pramipexole in the treatment of Parkinson's disease. Neuropsychiatr Dis Treat. 2008;4:337-352.
Patient Preference and Adherence

\section{Publish your work in this journal}

Patient Preference and Adherence is an international, peer-reviewed, open access journal focusing on the growing importance of patient preference and adherence throughout the therapeutic continuum. Patient satisfaction, acceptability, quality of life, compliance, persistence and their role in developing new therapeutic modalities and compounds to

\section{Dovepress}

optimize clinical outcomes for existing disease states are major areas of interest. This journal has been accepted for indexing on PubMed Central. The manuscript management system is completely online and includes a very quick and fair peer-review system. Visit http://www.dovepress.com/ testimonials.php to read real quotes from published authors. 